\title{
Organization's Conformity Assessment with Peter Senge's Learning Organization Principles in Municipality of Saveh: A Case Study
}

\author{
Vahid Jafari Sadeghi*1,Arash Jashnsaz ${ }^{2}$,Mehdi Honari Chobar ${ }^{3}$ \\ ${ }^{1}$ Departemant of Management, Payame Noor University, Karaj, Iran \\ ${ }^{2}$ Faculty of Industrial Engineering, Science \& Research Branch, Islamic Azad University, Arak, Iran \\ ${ }^{3}$ Faculty of Management, Science \& Research Branch, Islamic Azad University, Saveh, Iran
}

\begin{abstract}
The rapid development of science and technology severely is affected or will be affected on organizations. Municipalities as well as other organizations are required to align with the changes due to adapt to the social and technological changes. To align with the changes, organizations should put their base on the learning, learning how to learn and, how to elevate their employee's ability and this will not be possible unless organizations go forward to being the learning. This paper is based on five Senge's learning disciplines that identified organizations with personal mastery, mental models, building shared vision, team learning and systems thinking. For this reason, to assess the five components in current status, a descriptive - survey research have been conducted in the municipality of Saveh. A data collection tool has been questionnaire using Cronbach's alpha each question validity is extracted. Statistical society is 400 person, by using Cochran's formula 67 samples were selected. Eke for data analysis, T-test and SPSS software was used.

The result obtained of data analysis indicate that the current status of Saveh Municipality base on principles of in Peter Senge's learning organization is relatively desirable.
\end{abstract}

Keywords: Learning Organization, Peter Senge, Conformity Assessment, Municipality of Saveh.

\section{Introduction}

There are many differences between past and present organizations, managers are dealing with organizations that do not resemble the past. One of the key features of the new organization is their formation based on learning. Therefore, managers and employees are constantly learning and gaining new skills because the strength of each organization is proportional to amount of managers and employees training. Organizations previously lived in a stable environment and future events were pretty predictable, so that managers are able to plan in safe circumstances. But today, environment is rapidly changing and technological, economic, cultural and political changes quickly affected on organizations. Organization in order to survive, need to adapt to environmental changes and for adaptation, it have to make desirable change due to reach its goals. One of the presented strategies that respond to the rapid changes and complexity in the last decade is an idea of a learning organization. In this era only dynamic organization can be survived. (Asgari, 1383)

Learning Organization is a place "where people continually expand their capacity to create the results they truly desire, where new and expansive patterns of thinking are nurtured, where collective aspiration is set to free, and where people are continually learning how to learn together" (senge 2006, p.3). Since the municipal as one of the pillars of society have to be pioneer, development and institutionalization of learning organization on this important and impressive organization can in addition of its positive effects on self-organization may also have frequent positive effects on output. On this paper we are looking for evaluating status of Saveh municipal due to entitlement on five primary characteristics of a learning organization Peter Senge's models.

\section{Learning Organization}

Organizations depending on their specifications can be divided as in the following table:

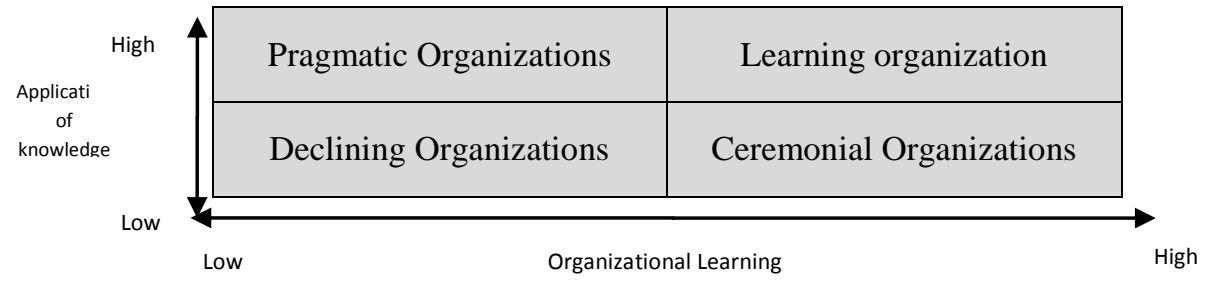

2.1. Deviation of organization base on learning and application 


\subsection{Declining Organizations}

In declining organizations emphasis neither learning nor acting. Such organizations, are only existed for the sake of receiving annual budget traditionally without any remarkable oversight on them. Obviously, these organizations can be found in state sector.

\subsection{Pragmatic Organizations}

Pragmatic organizations are resulted of short-time and limited thought and attitude. Constant slogan of managers in such organizations is further work. In these organizations are tried to fill deficiencies of knowledge and expertise by work hard.

\subsection{Ceremonial Organizations}

The ceremonial organizations are more into "Talking" rather than "action". Usually there are no new knowledge and scientific progress that managers of these organizations be unaware of it. It can be said dominant vision of the Ceremonial Organization is "learning for learning".

\subsection{Learning organization}

Learning organization is process of the both Science and practice. In learning organization, teaching and learning, neither "neglected" like pragmatic organization nor "targeted" Ceremonial organization. "Learning not for learning, but also for the improvement and development". (Ghahramani, 1380, 79-81)

\section{Principles of Learning Organization}

Senge's (1386) has been founded an idea of a learning organization base on five principles: 1-Personal mastery, 2-Mental models, 3-Building shared vision, 4-Team learning and 5- Systems thinking.

\subsection{Personal Mastery}

Organizations learn only through individuals who learn. Individual learning does not guarantee organizational learning. But without it no organizational learning occurs' (Senge 1990: 139). Personal mastery is the discipline of continually clarifying and deepening our personal vision, of focusing our energies, of developing patience, and of seeing reality objectively'. It goes beyond competence and skills, although it involves them. It goes beyond spiritual opening, although it involves spiritual growth. Mastery is seen as a special kind of proficiency. It is not about dominance, but rather about calling. Vision is vocation rather than simply just a good idea.

People with a high level of personal mastery live in a continual learning mode. They never 'arrive'. Sometimes, language, such as the term 'personal mastery' creates a misleading sense of definiteness, of black and white. But personal mastery is not something you possess. It is a process. It is a lifelong discipline. People with a high level of personal mastery are acutely aware of their ignorance, their incompetence, their growth areas. And they are deeply self-confident. Paradoxical? Only for those who do not see the "journey is the reward'. (Senge 1990: 142)

\subsection{Mental Models}

These are 'deeply ingrained assumptions, generalizations, or even pictures and images that influence how we understand the world and how we take action' (Senge 1990: 8). The discipline of mental models starts with turning the mirror inward; learning to unearth our internal pictures of the world, to bring them to the surface and hold them rigorously to scrutiny. It also includes the ability to carry on 'learningful' conversations that balance inquiry and advocacy, where people expose their own thinking effectively and make that thinking open to the influence of others. (Senge 1990: 9)

If organizations are to develop a capacity to work with mental models then it will be necessary for people to learn new skills and develop new orientations, and for theirs to be institutional changes that foster such change. 'Entrenched mental models... thwart changes that could come from systems thinking'. Moving the organization in the right direction entails working to transcend the sorts of internal politics and game playing that dominate traditional organizations. In other words it means fostering openness (Senge 1990: 273-286). It also involves seeking to distribute business responsibly far more widely while retaining coordination and control. Learning organizations are localized organizations.

\subsection{Building Shared Vision}

Peter Senge starts from the position that if any one idea about leadership has inspired organizations for thousands of years, 'it's the capacity to hold a share picture of the future we seek to create' (1990: 9). Such a 
vision has the power to be uplifting - and to encourage experimentation and innovation. Crucially, it is argued, it can also foster a sense of the long-term, something that is fundamental to the 'fifth discipline'.

When there is a genuine vision (as opposed to the all-to-familiar 'vision statement'), people excel and learn, not because they are told to, but because they want to. But many leaders have personal visions that never get translated into shared visions that galvanize an organization.

The practice of shared vision involves the skills of unearthing shared 'pictures of the future' that foster genuine commitment and enrolment rather than compliance. In mastering this discipline, leaders learn the counter-productiveness of trying to dictate a vision, no matter how heartfelt. (Senge 1990: 9)

Visions spread because of a reinforcing process. Increased clarity, enthusiasm and commitment rub off on others in the organization. 'As people talk, the vision grows clearer. As it gets clearer, enthusiasm for its benefits grow'. There are 'limits to growth' in this respect, but developing the sorts of mental models outlined above can significantly improve matters. Where organizations can transcend linear and grasp system thinking, there is the possibility of bringing vision to fruition.

\subsection{Team Learning}

This is a discipline of group interaction. Through techniques like dialogue and skillful discussion, teams transform their collective thinking, learning to mobilize their energies and ability greater than the sum of individual members' talents. The icon symbolizes the natural alignment of a learning-oriented team as the flight of a flock of birds.

Such learning is viewed as 'the process of aligning and developing the capacities of a team to create the results its members truly desire' (Senge 1990: 236). It builds on personal mastery and shared vision - but these are not enough. People need to be able to act together. When teams learn together, Peter Senge suggests, not only can there be good results for the organization, members will grow more rapidly than could have occurred otherwise.

\subsection{Systems Thinking}

In this discipline, people learn to better understand interdependency and change, and thereby to deal more effectively with the forces that shape the consequences of our actions. Systems thinking is based upon a growing body of theory about the behavior of feedback and complexity-the innate tendencies of a system that lead to growth or stability over time. Tools and techniques such as systems archetypes and various types of learning labs and simulations help people see how to change systems more effectively, and how to act more in tune with the larger processes of the natural and economic world. The circle in this icon represents the fundamental building block of all systems: the circular feedback loop underlying all growing and limiting processes in nature.

It is the discipline that integrates the others, fusing them into a coherent body of theory and practice. Systems theory's ability to comprehend and address the whole, and to examine the interrelationship between the parts provides, for Peter Senge, both the incentive and the means to integrate the disciplines.

Peter Senge advocates the use of 'systems maps' diagrams that show the key elements of systems and how they connect. However, people often have a problem 'seeing' systems, and it takes work to acquire the basic building blocks of systems theory, and to apply them to your organization. On the other hand, failure to understand system dynamics can lead us into 'cycles of blaming and self-defense: the enemy is always out there, and problems are always caused by someone else. (Bolam and Deal 1997: 27; see, also, Senge 1990: 231).

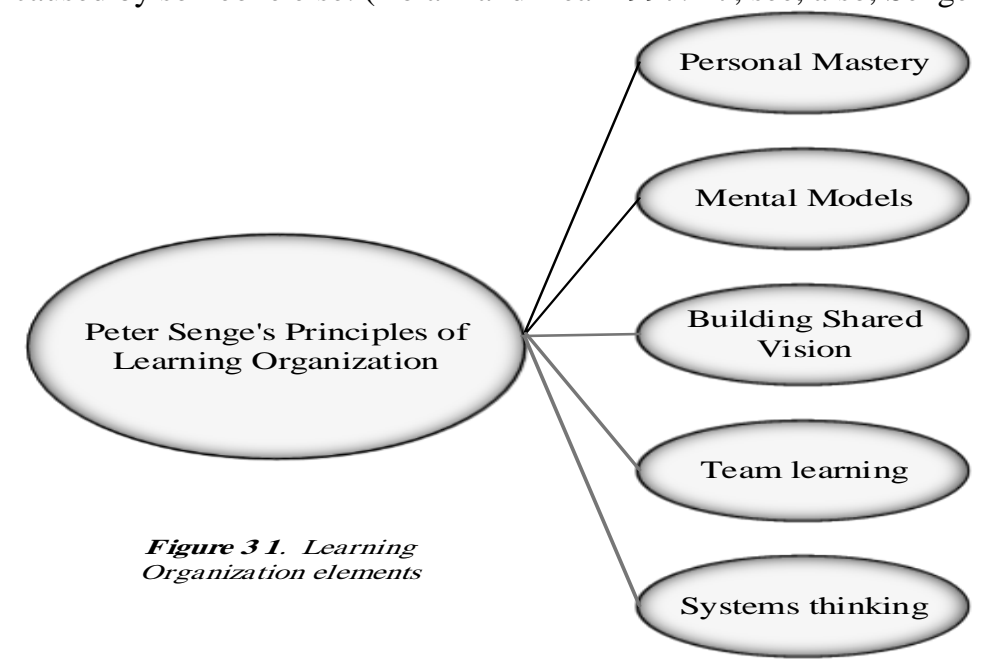




\section{Case Study: Municipality of Saveh}

This research, based on objective-oriented Categorizing, is considered as an applied research because its aim is to answer a question by presenting its application in problem solving. Statistical society is consisted of all employees working in universities, subordinate organizations and headquarter municipality in total 400 person. The sample size was determined 67 person by using the following formula:

$$
\begin{gathered}
n=\frac{z^{2} \mathrm{NPq}}{z^{2} \mathrm{Pq}+d^{2}(\mathrm{~N}-1)} \\
\mathrm{N}=400, \mathrm{P}=0.5, \mathrm{q}=(1-\mathrm{P}), \mathrm{d}=0.8, \mathrm{Z}=1.96
\end{gathered}
$$

Cronbach's alpha was used to calculate the reliability coefficient.

$$
\propto=\frac{N}{N-1}\left(1-\frac{\sum_{i=1}^{k} s_{i}^{2}}{\sigma^{2}}\right)
$$

$\mathrm{N}=$ Number of questions, $S_{i}{ }^{2}=$ Variance of i'th question, $\sigma^{2}=$ Total variance

By distributing 12 primary Questionnaire, Cronbach's alpha was calculated for each fifth discipline and high credit results was gained.

Considering the highest and lowest weight of each question with five and zero, spectrum is also a three part then:

$$
\frac{5}{3}=1.67
$$

If mean resulted was been between zero and 1.67, the status would be undesirable; if mean resulted was been between 1.67 to 3.33 , the status would be relatively desirable; and if mean resulted was been between 3.33 to 5 , the status would be desirable.

Questionnaires have had 41 questions that 7 question have been related with personal mastery, 7 questions have been related with mental models, 9 questions have been related with Building Shared Vision, 12 questions have been related with Team Learning and 6 questions have been related with Systems Thinking. To ensure that the sample results are generalizable to the statistical society, T-test have been used for each of the five disciplines.

\subsection{Statistical Analysis}

$$
\left\{\begin{array}{l}
\text { H0: } \mu 1=3.33 \\
\text { H1: } \mu 1 \neq 3.33
\end{array}\right.
$$

\begin{tabular}{|l|c|}
\hline \multicolumn{1}{|c|}{ Discipline } & Mean \\
\hline Personal Mastery & 2.65 \\
Mental Models & 2.98 \\
Building Shared Vision & 2.69 \\
Team Learning & 2.65 \\
Systems Thinking & 2.81 \\
\hline Total Status & 2.76 \\
\hline
\end{tabular}

Table 4.1. Mean of components of Learning Organization

\begin{tabular}{|l|c|c|c|c|}
\hline \multicolumn{1}{|c|}{ Discipline } & N & Mean & Std. Deviation & Std. Error Mean \\
\hline Personal Mastery & 7 & 2.6529 & 0.59601 & 0.22527 \\
Mental Models & 7 & 2.9786 & 0.30075 & 0.11367 \\
Building Shared Vision & 9 & 2.6922 & 0.16430 & 0.05477 \\
Team Learning & 12 & 2.6467 & 0.14711 & 0.04247 \\
Systems Thinking & 6 & 2.8117 & 0.14020 & 0.05724 \\
\hline Total Status & 5 & 2.7560 & 0.14135 & 0.06321 \\
\hline
\end{tabular}

Table 4.2. T-test for the current and desired status 
Organization's Conformity Assessment with Peter Senge's Learning Organization Principles in Municipality of Saveh

\begin{tabular}{|c|c|c|c|c|c|c|c|}
\hline \multirow{3}{*}{ Discipline } & \multicolumn{6}{|c|}{ Test Value $=0$} & \multirow{3}{*}{ Result } \\
\hline & \multirow[t]{2}{*}{$\mathrm{t}$} & \multirow[t]{2}{*}{ Df } & \multirow{2}{*}{ Sig. (2-tailed) } & \multirow{2}{*}{$\begin{array}{c}\text { Mean } \\
\text { Difference }\end{array}$} & \multicolumn{2}{|c|}{$\begin{array}{l}95 \% \text { Confidence Interval of } \\
\text { the Difference }\end{array}$} & \\
\hline & & & & & Lower & Upper & \\
\hline Personal Mastery & 11.776 & 6 & .000 & 2.65286 & 2.1016 & 3.2041 & $\begin{array}{l}\text { relatively } \\
\text { desirable }\end{array}$ \\
\hline Mental Models & 26.203 & 6 & .000 & 2.97857 & 2.7004 & 3.2567 & $\begin{array}{l}\text { relatively } \\
\text { desirable }\end{array}$ \\
\hline $\begin{array}{l}\text { Building Shared } \\
\text { Vision }\end{array}$ & 49.158 & 8 & .000 & 2.69222 & 2.5659 & 2.8185 & $\begin{array}{l}\text { relatively } \\
\text { desirable }\end{array}$ \\
\hline Team Learning & 62.321 & 11 & .000 & 2.64667 & 2.5532 & 2.7401 & $\begin{array}{l}\text { relatively } \\
\text { desirable }\end{array}$ \\
\hline Systems Thinking & 49.123 & 5 & .000 & 2.81167 & 2.6645 & 2.9588 & $\begin{array}{l}\text { relatively } \\
\text { desirable }\end{array}$ \\
\hline Total Status & 43.598 & 4 & .000 & 2.75600 & 2.5805 & 2.9315 & $\begin{array}{l}\text { relatively } \\
\text { desirable }\end{array}$ \\
\hline
\end{tabular}

Table 4.3. T-test for the current and desired status

Given the above table, as can be seen $\alpha \leq 0.05$; statistical null assumption will rejected with $95 \%$ confidence in all disciplines:

\subsubsection{Personal Mastery}

$$
P\left[2.1016 \leq \mu_{1} \geq 3.2041\right]=0.95
$$

Thus it can be concluded that there are no statistically significant difference between current and desired status in accordance with Peter Senge's personal mastery discipline of learning organization in municipality of Saveh and finally the status is relatively desirable.

\begin{tabular}{|c|c|c|c|c|c|}
\hline \multirow{2}{*}{$\begin{array}{c}\text { Q } \\
\text { No. }\end{array}$} & Assessed Components of Personal Mastery & \multirow{2}{*}{ Mean } & \multicolumn{3}{|c|}{ Quality Status of Answers } \\
\cline { 5 - 6 } & & & Desirable & $\begin{array}{c}\text { Relatively } \\
\text { Desirable }\end{array}$ & Undesirable \\
\hline 1 & Importance of training program & 2.93 & & $*$ & \\
\hline 2 & Ability to Lecture & 1.97 & & $*$ & \\
\hline 3 & The need for conference & 1.91 & & $*$ & \\
\hline 4 & Believe to increase personal masteries & 2.65 & & $*$ & \\
\hline 5 & Encourage the development personal abilities & 2.54 & & $*$ & \\
\hline 6 & Interest in promotion of personal capabilities & 3.62 & $*$ & & \\
\hline 7 & Effort to promote masteries in line with organizational needs & 2.95 & & $*$ & \\
\hline & The total mean of Personal Mastery & 2.65 & & $*$ & $*$ \\
\hline
\end{tabular}

Table 4.4. Mean and status of each components of Personal Mastery

\subsubsection{Mental Models}

$$
P\left[2.7004 \leq \mu_{1} \geq 3.2567\right]=0.95
$$

Thus it can be concluded that there are no statistically significant difference between current and desired status in accordance with Peter Senge's mental models discipline of learning organization in

\begin{tabular}{|c|c|c|c|c|c|}
\hline \multirow{2}{*}{$\begin{array}{c}\text { Q } \\
\text { No. }\end{array}$} & \multirow[b]{2}{*}{ Assessed Components of Mental Models } & \multirow[b]{2}{*}{ Mean } & \multicolumn{3}{|c|}{ Quality Status of Answers } \\
\hline & & & Desirable & $\begin{array}{l}\text { Relatively } \\
\text { Desirable }\end{array}$ & Undesirable \\
\hline 8 & Importance of diversity of perspectives & 3.12 & & * & \\
\hline 9 & Possibility to the express thoughts and opinions & 2.69 & & * & \\
\hline 10 & Opportunity to discuss with other employees & 2.88 & & * & \\
\hline 11 & Embracing new ideas & 2.86 & & * & \\
\hline 12 & Bias against criticism & 3.42 & * & & \\
\hline 13 & tend to investigate distinct viewpoints & 2.61 & & * & \\
\hline 14 & Afraid of cataclysmic & 3.27 & & * & \\
\hline & The total mean of Mental Models & 2.98 & & $*$ & \\
\hline
\end{tabular}
municipality of Saveh and finally the status is relatively desirable.

Table 4.5. Mean and status of each components of Mental Models 


\subsubsection{Building Shared Vision}

$$
P\left[2.5659 \leq \mu_{1} \geq 2.8185\right]=0.95
$$

Thus it can be concluded that there are no statistically significant difference between current and desired status in accordance with Peter Senge's building shared vision discipline of learning organization in municipality of Saveh and finally the status is relatively desirable.

\begin{tabular}{|c|c|c|c|c|c|}
\hline \multirow{2}{*}{$\begin{array}{c}\text { Q } \\
\text { No. }\end{array}$} & Assessed Components of Building Shared Vision & \multirow{2}{*}{ Mean } & \multicolumn{3}{|c|}{ Quality Status of Answers } \\
\cline { 5 - 6 } & Building organization vision & & Desirable & $\begin{array}{c}\text { Relatively } \\
\text { Desirable }\end{array}$ & Undesirable \\
\hline 15 & Participation in building shared vision & 2.64 & & $*$ & \\
\hline 16 & Promising to shared vision & 2.42 & & $*$ & \\
\hline 17 & Delivering shared vision & 2.80 & & $*$ & \\
\hline 18 & Have plan to achieve the vision & 2.51 & & $*$ & \\
\hline 19 & Activities to achieve the vision & 2.61 & & $*$ & \\
\hline 20 & Commitment to the shared vision & 2.86 & & $*$ & \\
\hline 21 & Learning in order to achieve the vision & 2.73 & & $*$ & \\
\hline 22 & Support of vision & 2.73 & & $*$ & \\
\hline 23 & The total mean of Building Shared Vision & 2.93 & & $*$ & $*$ \\
\hline
\end{tabular}

Table 4.6 Mean and status of each components of Building Shared Vision

\subsubsection{Team Learning}

$$
P\left[2.5532 \leq \mu_{1} \geq 2.7401\right]=0.95
$$

Thus it can be concluded that there are no statistically significant difference between current and desired status in accordance with Peter Senge's team learning discipline of learning organization in municipality of Saveh and finally the status is relatively desirable.

\begin{tabular}{|c|c|c|c|c|c|}
\hline \multirow{2}{*}{$\begin{array}{c}\text { Q } \\
\text { No. }\end{array}$} & Assessed Components of Team Learning & \multirow{2}{*}{ Mean } & \multicolumn{3}{|c|}{ Quality Status of Answers } \\
\cline { 5 - 6 } & & & Desirable & $\begin{array}{c}\text { Relatively } \\
\text { Desirable }\end{array}$ & Undesirable \\
\hline 24 & Learning as a priority in all levels & 2.65 & & $*$ & \\
\hline 25 & Annual training for all employees & 2.58 & & $*$ & \\
\hline 26 & Creating working groups & 2.74 & & $*$ & \\
\hline 27 & Formation of working groups from various sectors & 2.70 & & $*$ & \\
\hline 28 & The necessary expertise for members of the working group & 2.84 & & $*$ & \\
\hline 29 & Assistance to each other & 2.74 & & $*$ & \\
\hline 30 & Trust each other & 2.82 & & $*$ & \\
\hline 31 & Exercises for better Team working & 2.47 & & $*$ & \\
\hline 32 & Learning how to work in a group & 2.46 & & $*$ & \\
\hline 33 & Learning from each other & 2.50 & & $*$ & \\
\hline 34 & Open exchange of ideas at meetings & 2.80 & & $*$ & $*$ \\
\hline 35 & Encourage to solve problems collectively & 2.46 & & $*$ & $*$ \\
\hline
\end{tabular}

\subsubsection{Systems Thinking}

Table 4.7. Mean and status of each components of Team Learning

$$
P\left[2.6645 \leq \mu_{1} \geq 2.9588\right]=0.95
$$

Thus it can be concluded that there are no statistically significant difference between current and desired status in accordance with Peter Senge's systems thinking discipline of learning organization in municipality of Saveh and finally the status is relatively desirable. 


\begin{tabular}{|c|c|c|c|c|c|}
\hline \multirow{2}{*}{$\begin{array}{c}\text { Q } \\
\text { No. }\end{array}$} & Assessed Components of Systems Thinking & \multirow{2}{*}{ Mean } & \multicolumn{3}{|c|}{ Quality Status of Answers } \\
\cline { 5 - 6 } & & & Desirable & $\begin{array}{c}\text { Relatively } \\
\text { Desirable }\end{array}$ & Undesirable \\
\hline 36 & Systematic thinking of manager & 2.99 & & $*$ & $*$ \\
\hline 37 & Encourage employees to comprehensive thinking & 2.65 & & $*$ & $*$ \\
\hline 38 & Awareness of impact of the decisions on other sectors & 2.76 & & $*$ & $*$ \\
\hline 39 & The root of problem has not got just one particular cause & 2.70 & & $*$ & $*$ \\
\hline 40 & The interaction with organization's components & 2.97 & & $*$ & $*$ \\
\hline 41 & The interaction with the environment & 2.80 & & $*$ & $*$ \\
\hline
\end{tabular}

Table 4.8. Mean and status of each components of Systems Thinking

\subsubsection{Total Status}

$$
P\left[2.5805 \leq \mu_{1} \geq 2.9315\right]=0.95
$$

As it is shown in table 9, the total status of municipality of Saveh is relatively desirable that mental models have got maximum desirability (2.98) and both personal mastery and team learning have got minimum desirability (2.65). (Figure 2)

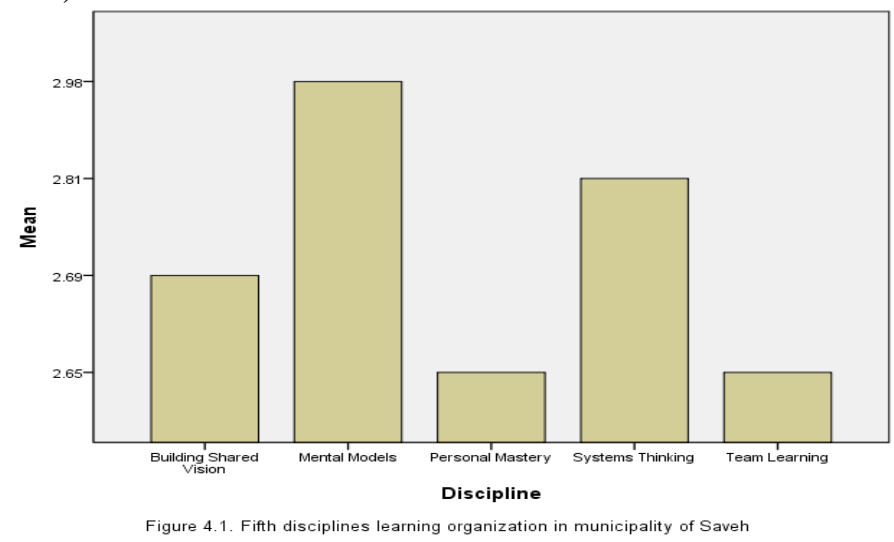

\section{Conclusion}

The main purpose of this paper was evaluating current and desired status in learning organization characteristics municipality of Saveh. The research findings has been showed that there are significant differences between current and desired status in terms of learning organization characteristics. Generally the most important infrastructure needed to create a learning organization can be summarized thus:

- Strong, open, participative and understanding organizational culture that promotes learning and innovation.

- Leaders and staff with shared vision, empowered and learning supportive characteristics.

- Creating a dynamic, organic, flat and with minimal hierarchy organizational structures.

- Transition from partial visual to holistic view and see the organization as an integrated whole.

Studies have shown to promote the current status into deserves status, it is needed to create an attraction for individuals to be more creative and innovative. Development of personal mastery is a continuous process oversee of all things that not exist in humans. Should be considered using information and communication technologies caused continual awareness of the internal and external organization's environment.

The municipality must provide circumstances to teach managers and staff due to assay their mental models without provoking defensive mechanism and explain arguments that has made them unique. Also it should motivate managers and staff in order to test emphasized theories. For achieving such capacities, municipalities have to modify beliefs and mental models that has prevented to implement new theories and knowledge in municipality.

The results of this paper emphasis the fact that the goals and objectives are formulating in another place which has been conveyed according to guidelines and style sheets; and this is conduct of traditional organizations. In such organizations employees have not felt, in their Role Playing, they need to act as a team and help each other anymore. 
At the end as Pedlar and colleagues (1988) mentioned, the learning organization is really an idealistic position. The possibility to observe it as a meaningful concept is rare and that is why it is more than a definition in a learning organization. Generally the changes in process of turning to learning organization are like the waves in a cup of tea; in other words the learning organization is making the waves in the culture base. The managers on these organizations need to create a culture with the base of critics, research, innovation and learning.

\section{References}

[1]. Akhavan, Peyman, Jafari, 1385, The learning organizations the requisite of knowledge era, Tadbir, No.169

[2]. Asgari, Ahmad, 1383, Making learning organization, No.91\&92

[3]. Azar, Adel Momeni, Mansour, 1391, Statistics and its application in management, second version, sixteen print, Samt publication, Tehran

[4]. Bolman, L. G. and Deal, T. E. (1997) Reframing Organizations. Artistry, choice and leadership 2e, San Francisco: Jossey-Bass. 450 pages.

[5]. DePree, M. (1990) Leadership is an Art, New York: Dell.

[6]. Ghahramani, Mohammad, 2001, The learning organization a random of semi century, Magazine of management \& improvement. No.10

[7]. Lopez‘ Susana Perez. \& Montes Jose‘ Manuel. 2005. Organization learning a determining factor in business performance. The learning organization:V.16 N.3.

[8]. Marquard‘ M. 2011. Building the learning organization. New York: Technology-based learning boca raton. F1: St.lucie.

[9]. Ortendbland، Anders. 2004. The learning organization. London: continuum.

[10]. Peck, M. S. (1990) The Road Less Travelled, London: Arrow.

[11]. Senge, P. (1998) 'The Practice of Innovation', Leader to Leader 9http://pfdf.org/leaderbooks/121/summer98/senge.html

[12]. Sange, Peter \& Colleagues, 1386, The dance of change- the challenges of stable change in organization, Translateh Hossein Akbari\& Masud Soltani, Tehran, Asia Publication

[13]. Senge' P.M. 2010. The fifth discipline: The art and practice of the learning organization. London: century business.

[14]. Sennett, R. (1998) The Corrosion of Character. The personal consequences of work in the new capitalism, New York: Norton

[15]. Smith, M. K. (2001) 'Peter Senge and the learning organization', the encyclopedia of informal education

[16]. Yang، Baity in. \& Watkins` Karen. \& Marsike، Victoria. 2004. The construct of The learning organization: dimension‘ meaturement And validation. Human resurce development: V.15، N.1‘ pp.31-55.

[17]. Yang، A. David‘ \& O. Stephen‘ W. \& Mary ‘ A. 1999. Organization learning capability. New York: Oxford University press. 